13

\title{
Исследование волоконно-оптических элементов на основе фотоактивной полимерной композиции для сенсорных применений
}

\author{
(C) А.С. Матросова ${ }^{1,2}$, С.К. Евстропьев ${ }^{2}$, Л.Ю. Миронов ${ }^{2}$, Н.В. Никоноров ${ }^{2}$, А.В. Комаров ${ }^{1}$, В.В. Демидов ${ }^{1, \Upsilon^{\top}}$ \\ ${ }^{1}$ НПО гОИ им. С.И. Вавилова, \\ 192171 Санкт-Петербург, Россия \\ ${ }^{2}$ Университет ИТМО, \\ 197101 Санкт-Петербург, Россия \\ ฯe-mail: demidov@goi.ru
}

Поступила в редакцию 26.04.2019 г.

В окончательной редакции 26.04.2019 г.

Принята к публикации 16.05.2019 г.

Экспериментально исследован макет волоконно-оптического сенсорного устройства для измерения температуры окружающей среды, принцип работы которого основан на температурном тушении люминесценции. В качестве чувствительного элемента сенсора использовалась конструкция из многомодового волоконного световода с коэффициентом пропускания более $90 \% / \mathrm{m}$ в спектральной области от 350 до $650 \mathrm{~nm}$ и кварцевого капилляра, заполненного фотоактивной полимерной композицией на основе эпоксиакрилата и комплексного соединения европия с 2-нафтоилтрифторацетоном и триоктилфосфиноксидом. Установлен экспоненциально спадающий характер зависимости интенсивности люминесценции фотоактивной композиции в составе сенсора (длина волны возбуждения $355 \mathrm{~nm}$, длина волны люминесценции $615 \mathrm{~nm}$ ) от температуры в диапазоне значений от 20 до $100^{\circ} \mathrm{C}$. Определено квазилинейное изменение интенсивности люминесценции от мощности вводимого ультрафиолетового излучения.

Ключевые слова: сенсор, волоконно-оптический элемент, европий, люминесценция, фотоактивность.

DOI: $10.21883 /$ OS.2019.10.48379.146-19

\section{Введение}

На протяжении двух последних десятилетий на практике активно внедряются сенсорные устройства различной конструкции для непрерывного контроля параметров окружающей среды (температуры, давления, деформации, вибрации и т. д.). Из всего многообразия существующих датчиков выделяют волоконно-оптические, преимуществами которых относительно аналогичных по функциям устройств другого типа являются возможность детектирования параметров внешней среды в удаленных и труднодоступных местах, устойчивость к воздействию электромагнитного излучения и радиации, компактность, надежность, высокая точность измерений [1].

Для ряда приложений перспективным представляется использование волоконно-оптических датчиков люминесцентного типа, отличающихся быстродействием и высокой чувствительностью [2]. Функционирование подобных сенсоров базируется на использовании эффекта люминесценции, достигаемого за счет легирования материала сердцевины или оболочки световода фосфором или ионами редкоземельных металлов, которые при фотовозбуждении испускают смещенное по частоте излучение [3]. Вместе с тем область применения волоконно-оптических датчиков люминесцентного типа не ограничивается измерениями параметров окружающей среды, в частности температуры [4]. Такие устрой- ства востребованы, в том числе для детектирования ультрафиолетового (УФ) излучения [5-8].

Развитие технологии получения функциональных материалов открывает возможности для использования в люминесцентных датчиках фотополимерных композиций, активированных ионами редкоземельных металлов, что значительно упрощает конструкцию и способ изготовления сенсоров. Так, в работе [9] сообщается о применении в качестве термочувствительного материала фотополимера (эпоксиакрилата), в состав которого введены комплексные соединения европия $\left(\mathrm{Eu}^{3+}\right)$ с 2-нафтоилтрифторацетоном и триоктилфосфиноксидом. Как оказалось, эта композиция характеризуется сильным поглощением в ближней УФ области спектра и ярко выраженной люминесценцией на длине волны $\lambda=615 \mathrm{~nm}$, соответствующей полосе электронного перехода ${ }^{5} D_{0} \rightarrow{ }^{7} F_{2}$. Механизм регистрации изменения температуры окружающей среды датчиком на основе такой композиции заключается в определении времени жизни люминесценции возбужденных УФ излучением ионов $\mathrm{Eu}^{3+}$. В упомянутой работе [9] продемонстрировано трехкратное уменьшение времени жизни люминесценции ионов $\mathrm{Eu}^{3+}$ при увеличении температуры от 20 до $100^{\circ} \mathrm{C}$.

Целью настоящей работы было создание и исследование макетов волоконно-оптических элементов (ВОЭ) простой конструкции, принцип работы которых построен на явлении температурного тушения люминесценции, 
для измерения температуры окружающей среды и детектирования УФ излучения.

\section{Объект исследования}

Для создания макета термочувствительного ВОЭ была синтезирована фотоактивная полимерная композиция с химическим составом, идентичным описываемому в работе [9]. Основной раствор комплексного соединения $\mathrm{Eu}^{3+}$ был получен смешиванием $\mathrm{EuCl}_{3} \cdot 6 \mathrm{H}_{2} \mathrm{O}\left(3 \cdot 10^{-2} \mathrm{M}\right.$, „Завод редких металлов“, г. Новосибирск, 99\%) с 2-нафтоилтрифторацетоном $\left(9 \cdot 10^{-2}\right.$ M, Sigma-Aldrich, 99\%) и триоктилфосфиноксидом $\left(9 \cdot 10^{-2} \mathrm{M}\right.$, Sigma-Aldrich, 99\%) в $100 \mathrm{ml}$ диметилформамида („Вектон“, г. Санкт-Петербург, 99\%). Спустя 10-15 min после полного растворения исходных веществ в диметилформамиде без какой-либо дополнительной обработки были образованы комплексы $\mathrm{Eu}^{3+}$. Полученный раствор комплексного соединения $\mathrm{Eu}^{3+}$ (20 vol.\%) использовался для создания фотоактивной композиции путем его механического смешивания с полимером на основе эпоксиакрилата марки DeSolite 3471-3-14 (Royal DSM, 80 vol.\%).

На рис. 1 приведены спектры возбуждения и люминесценции синтезированной фотоактивной композиции. Спектр возбуждения люминесценции был измерен на спектрофотометре Perkin LAMBDA 650 UV/Vis. Для исследования спектра люминесценции применялся флуоресцентный спектрофотометр Perkin Elmer LS-50B.

Конструкция ВОЭ состояла из многомодового волоконного световода и кварцевого капилляра с внутренним диаметром $0.45 \mathrm{~mm}$ длиной $2 \mathrm{~cm}$, заполненного термочувствительным материалом. В связи с необходимостью передачи одновременно возбуждающего излучения УФ диапазона и преобразованного фотоактивной композицией излучения видимого диапазона для экспериментального исследования был выбран световод с сердцевиной из кварцевого стекла с низким содержанием ОН-групп диаметром $400 \mu \mathrm{m}$, который характеризовался коэффициентом пропускания более 90\%/m в спектральной области от 350 до $650 \mathrm{~nm}$. Два отрезка такого световода длиной $7 \mathrm{~m}$ каждый с механически очищенными от защитного покрытия и отполированными торцами были помещены с двух противоположных сторон в кварцевый капилляр вплотную к фотоактивной композиции. Отверждение композиции осуществлялось под воздействием излучения УФ лампы в течение $1 \mathrm{~min}$. На рис. 2 приведена фотография конструктивных элементов ВОЭ в процессе возбуждения люминесценции фотоактивной полимерной композиции.

Заметим, что синтезированная фотоактивная композиция характеризовалась высокой оптической плотностью, позволяющей осуществлять возбуждение люминесценции и передачу преобразованного оптического сигнала в сравнительно небольшом объеме. По этой причине
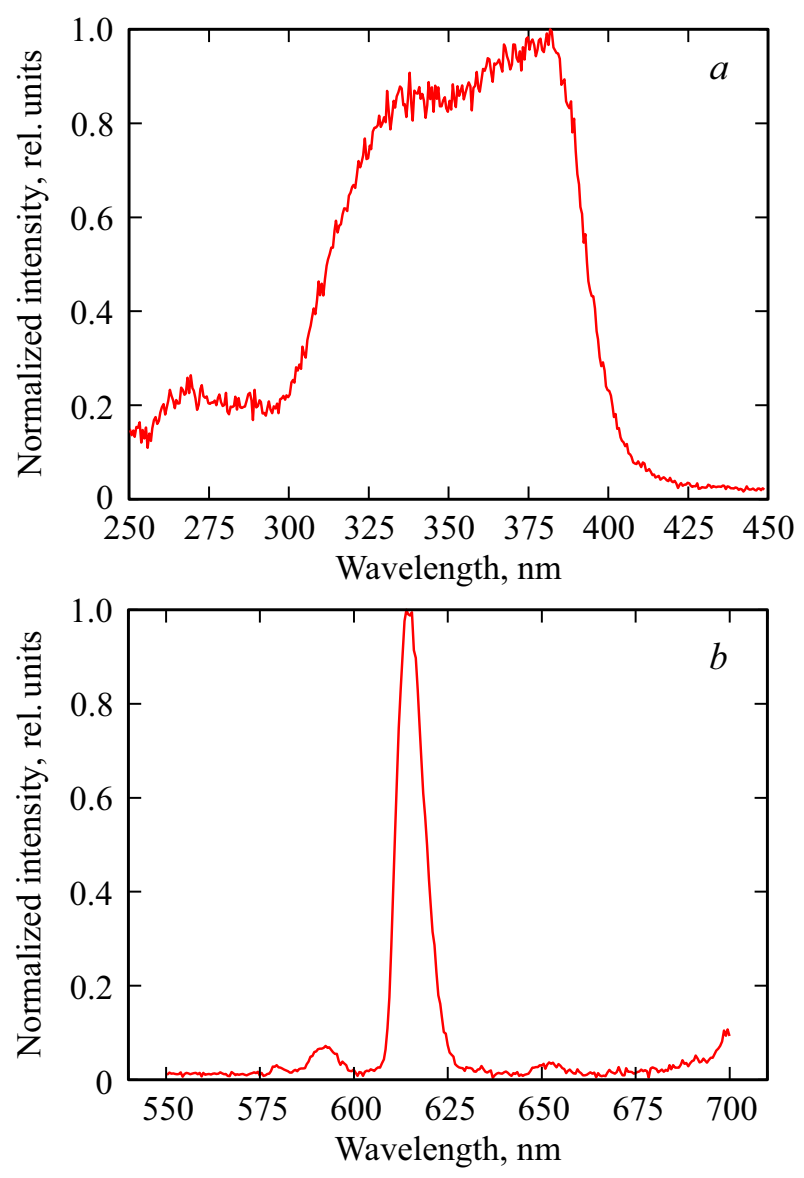

Рис. 1. Спектры возбуждения люминесценции $\left(\lambda_{\mathrm{ex}}=350 \mathrm{~nm}\right) \quad(a)$ и люминесценции $\quad\left(\lambda_{\mathrm{em}}=615 \mathrm{~nm}\right) \quad(b)$ комплексов $\mathrm{Eu}^{3+}$ в составе фотоактивной полимерной композиции.

отрезки световода с двух противоположных сторон капилляра были подведены почти вплотную друг к другу.

\section{Методика проведения эксперимента и результаты исследования}

Исследование чувствительности ВОЭ к изменению температуры окружающей среды проводилось на экспериментальной установке, схематическое изображение которой представлено на рис. 3 .

ВОЭ фиксировался на предметном столике таким образом, чтобы излучение от ксеноновой лампы после прохождения через монохроматор и согласующие элементы фокусировались на входном торце „возбуждающего“ световода. Направленный ввод УФ излучения с длиной волны $\lambda=355 \mathrm{~nm}$ в полость капилляра, заполненную фотоактивной композицией, способствовал проявлению эффекта люминесценции, соответствующей полосе электронного перехода ${ }^{5} D_{0} \rightarrow{ }^{7} F_{2}$. Регистрация преобразованного композицией оптического сигнала на выходном торце „сигнального“ световода осуществлялась кремниевым фотоприемником. 


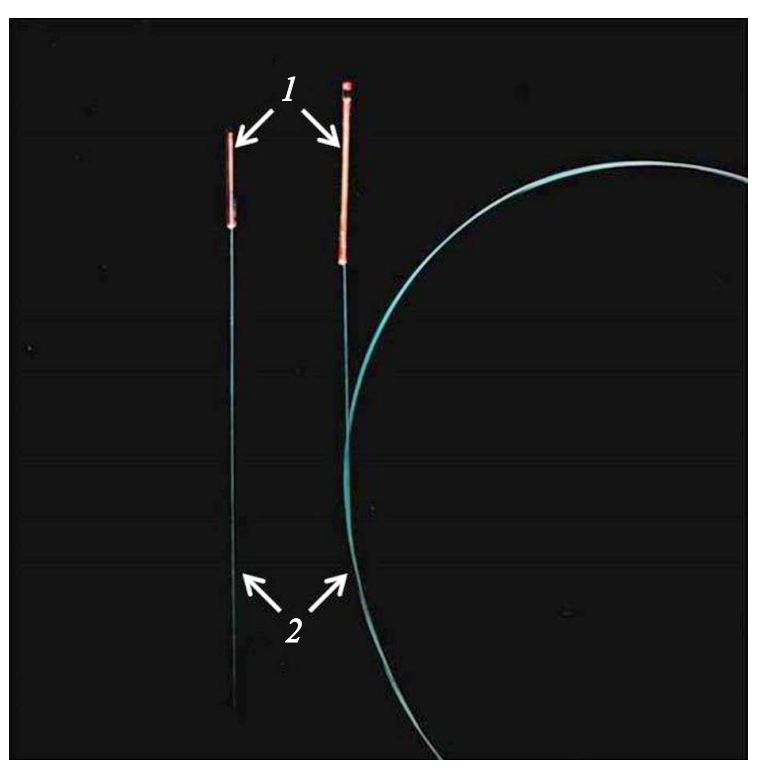

Рис. 2. Фотография ВОЭ под действием возбуждающего люминесценцию излучения: 1 - кварцевый капилляр, заполненный фотоактивной полимерной композицией, 2 - многомодовый волоконный световод с сердцевиной диаметром $400 \mu \mathrm{m}$.

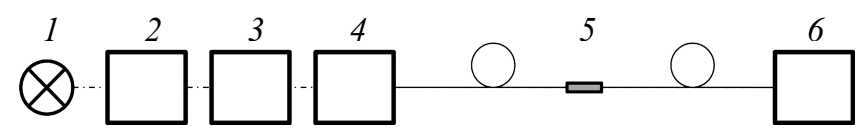

Рис. 3. Схема экспериментальной установки для исследования чувствительности ВОЭ к изменению температуры: 1 - ксеноновая лампа XBO $150 \mathrm{~W} / 4$ (OSRAM, Германия), 2 - монохроматор МДР-23 (ЛОМО, Россия), 3 - модулятор MC1000 (Thorlabs, Германия), 4 - элементы согласования, 5 - ВОЭ, 6 - фотоприемник FPD510-FV (Menlo Systems, Германия).

Для исследования температурной зависимости интенсивности оптического сигнала на выходе ВОЭ капилляр с чувствительным материалом помещался в климатическую камеру Feutron 3524/58 (Германия). В результате серии испытаний был установлен экспоненциально спадающий характер изменения интенсивности люминесценции фотоактивной полимерной композиции в составе ВОЭ в температурном диапазоне от 20 до $100^{\circ} \mathrm{C}$ (рис. 4, a). При температурах выше $100^{\circ} \mathrm{C}$ использование рассматриваемой композиции в качестве чувствительной среды оказалось нежелательным вследствие деградации свойств комплексного соединения $\mathrm{Eu}^{3+} \mathrm{c}$ 2-нафтоилтрифторацетоном и триоктилфосфиноксидом.

Отметим, что на достоверность показаний фотоприемника, регистрировавшего распространявшийся по ВОЭ и преобразованный фотоактивной композицией оптический сигнал, существенное влияние оказывало постороннее излучение. По этой причине для предотвращения искажения результатов испытаний доступ света к капилляру с чувствительным материалом был ограничен.
Исходя из тех соображений, что полученное комплексное соединение $\mathrm{Eu}^{3+}$ с 2-нафтоилтрифторацетоном и триоктилфосфиноксидом характеризуется сильным поглощением в области ближнего УФ диапазона и имеет яркую люминесценцию в видимой части спектра, была экспериментально изучена возможность применения описанного ВОЭ в качестве детектора УФ излучения в окружающей среде. Для проведения такого исследования был изготовлен макет ВОЭ с конструкцией, несколько отличной от той, которая использовалась в предыдущем эксперименте. К кварцевому капилляру с идентичными геометрическими параметрами был подведен один отрезок многомодового волоконного световода длиной $2 \mathrm{~m}$. Излучение ксеноновой лампы фокусировалось непосредственно на полость капилляра, заполненную фотоактивной полимерной композицией. Фотоприемник регистрировал интенсивность оптического сигнала в зависимости от мощности излучения ксеноновой лампы. В результате серии опытов был определен квазилинейный характер (параметр достоверности аппроксимации $R^{2} \approx 0.99$ ) зависимости интенсивности оптического сигнала на выходе ВОЭ от мощности вводимого УФ излучения, что наглядно проиллюстрировано на рис. $4, b$.
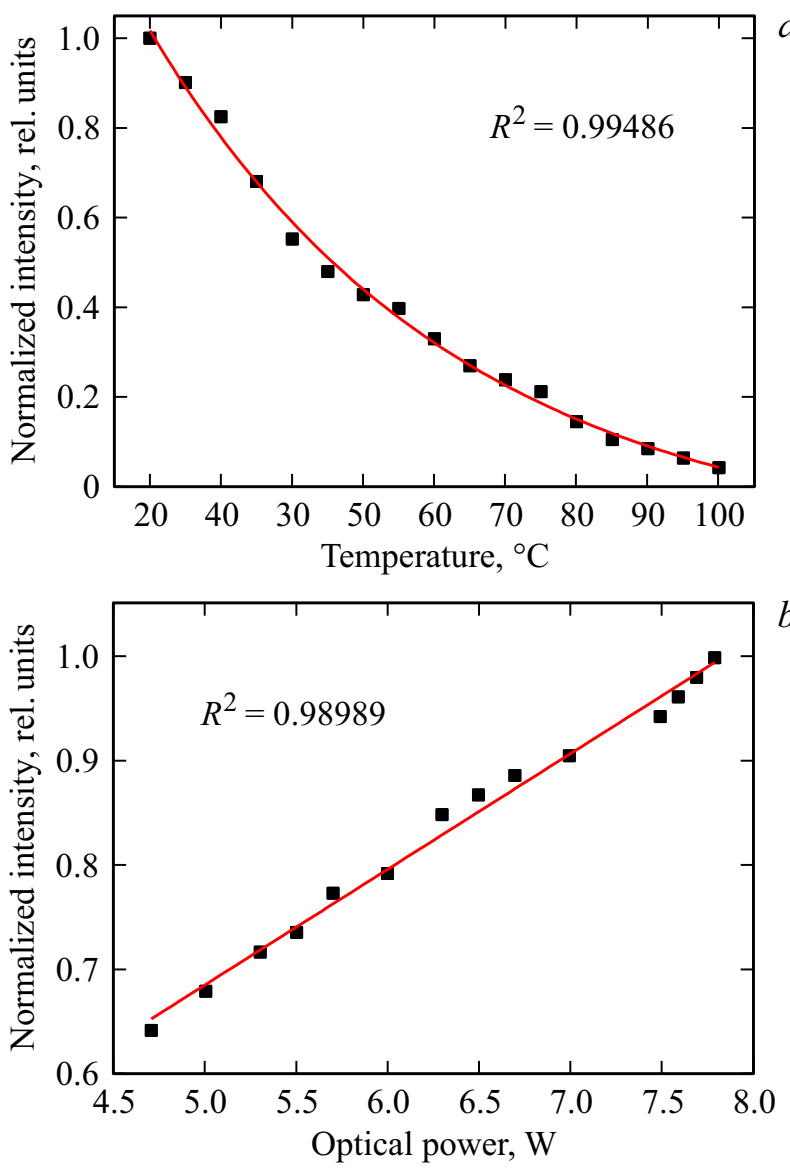

Рис. 4. Зависимость интенсивности оптического сигнала на выходе ВОЭ от температуры $(a)$ и мощности вводимого УФ излучения $(b)$. 


\section{Заключение}

Таким образом, проведено экспериментальное исследование макета волоконно-оптического сенсорного устройства на основе фотоактивной композиции из эпоксиакрилата и комплексного соединения $\mathrm{Eu}^{3+} \mathrm{c}$ 2-нафтоилтрифторацетоном и триоктилфосфиноксидом для измерения температуры окружающей среды. Установлен экспоненциально спадающий характер зависимости интенсивности люминесценции фотоактивной композиции в составе сенсора от температуры в диапазоне значений от 20 до $100^{\circ} \mathrm{C}$, что обусловлено ее температурным тушением. В дополнение, обнаружено квазилинейное изменение интенсивности люминесценции от мощности вводимого УФ излучения, что позволяет рассматривать такое устройство в качестве детектора УФ излучения в окружающей среде.

\section{Финансирование работы}

Исследование спектрально-люминесцентных свойств фотоактивной полимерной композиции выполнено при поддержке гранта Российского научного фонда (проект № 19-19-00596). Исследование чувствительности волоконно-оптического элемента на основе фотоактивной полимерной композиции к изменению температуры выполнено при поддержке гранта Российского научного фонда (проект № 18-12-00075).

\section{Конфликт интересов}

Авторы заявляют, что у них нет конфликта интересов.

\section{Список литературы}

[1] Grattan K.T.V., Sun T. // Sensors and Actuators A: Physical. 2000. V. 82. N 1-3. P. 40-61.

[2] Jackson R.G. Novel sensors and sensing. London: CRC Press, 2004. $512 \mathrm{p}$.

[3] Grattan K.T.V., Meggitt B.T. // Optical Fiber Sensor Technology: V. 4. Dordrecht: Springer Netherlands, 1999. 336 p.

[4] McSherry M., Fitzpatrick C., Lewis E. // Sensor Review. 2005. V. 25. N 1. P. 56-62.

[5] Fitzpatrick C., O'Donoghue C., Lewis E. // Measurement Science and Technology. 2003. V. 14. N 8. P. 1477-1483.

[6] Zmojda J., Kochanowicz M., Miluski P., Dorosz D. // Fibers. 2014. V. 2. N 2. P. $150-157$.

[7] Agafonova D.S., Kolobkova E.V., Ignatiev A.I., Nikonorov N.V., Shakhverdov T.A., Shirshnev P.S., Sidorov A.I., Vasiliev V.N. // Optical Engineering. 2015. V. 54. N 11. P. 117107.

[8] Yan Y., Zhang X., Li H., Ma Y., Tianci X., Qin Z., Liu S., Sun W., Lewis E. // Sensors. 2018. V. 18. N 11. P. 3754.

[9] Mironov L.Yu., Evstropiev S.K. // Optical Engineering. 2019. V. 58. N 2. P. 027113. 